Elsevier required licence: (c) $<2018>$. This manuscript version is made available under the CC-BY-NC-ND 4.0 license http://creativecommons.org/licenses/bync-nd/4.0/ 


\title{
Bernard Roth: The Early Days of the Design Division at Stanford, and the Beginnings of Research in Robotics
}

\author{
Kenneth J. Waldron \\ Professor (Research) Emeritus, Stanford University, and Professor, University of \\ Technology, Sydney
}

Abstract: This paper comprises a review of Bernard Roth's technical contributions and contributions to his professional community. Particular attention is paid to his role in the establishment of the unique design program of the Department of Mechanical Engineering at Stanford University. Another theme is the creation of one of the very first research programs in digitally controlled robotics in the Stanford Artificial Intelligence Laboratory.

No review of Roth's career would be complete without touching on the numerous fundamental contributions to research in linkages and robotics. At the same time it is not possible in a work on this type to examine every one of his publications and other contributions. We have endeavored to select the most important, but that is, of course, a personal judgment.

\section{Introduction}

Over a career that has now spanned 55 years at Stanford University, Bernard Roth has influenced many areas of machine design and robotics, and also creativity and selfrealization. This paper constitutes a review of that career by one who was in a position to witness much of it first as a doctoral student supervised by him, then as a fellow researcher in the same general field, and more recently as a colleague in the same academic unit.

Roth's contributions are diverse. I am sure there will be those who feel I have not done justice to some area, or other. What I do hope to produce is a contribution that will help to document this remarkable career, and the history of an important period of technical development in which computers have gone from being an exotic and ill- 
understood tool to being essential components of the machines and systems that surround us and support our everyday lives.

\section{The Design Division of the Department of Mechanical Engineering}

Bernard Roth joined the Design Division of the Department of Mechanical Engineering at Stanford University in 1962 as an assistant professor. He was fresh from completing his PhD from Columbia University as a student of Ferdinand Freudenstein. At that time the faculty members of the Design Division included Professor John Arnold, who had been recruited from MIT to lead the group. Arnold was a joint appointment between Mechanical Engineering and Business. He had gained a reputation for his unique approach to project based teaching using imaginary planet environments for which basic physical parameters like gravity were different to those of Earth.

The others in the group included Robert McKim, who had a bachelor's degree in mechanical engineering from Stanford, and a master's degree in product design from Pratt Institute. Arnold had brought McKim in to lead product design. He had started as a part-time lecturer and had just moved onto a full-time position in 1962. Peter Bulkeley, was an acting assistant professor because he was still finishing his doctoral thesis with Professor J. Norman Goodier in Applied Mechanics, which was a separate department at the time. Robert Keller, was also appointed as acting assistant professor and was finishing his doctorate. He was interested in applications of analog computing to machine design and was supervised by Arnold.

At the time, faculty members whose teaching and research interests were in thermodynamics, heat transfer and fluid mechanics dominated the Department of Mechanical Engineering at Stanford. There was a small group identified as nuclear 
engineering who identified with heat transfer to a much greater extent than they did machine design. In fact, when the nuclear engineering program was phased out a few years later, those faculty members simply merged into the heat transfer group.

John Arnold was the architect of the Design Division, and the senior mentor to the young faculty members who joined him to make up the group. It was Arnold's conception to combine product design with mechanical design. The Stanford Department of Mechanical Engineering was, and still is, unique in incorporating research and teaching in product design. That feature of the group has certainly influenced Roth's career and life. It was a serious blow when Arnold died in 1963 while travelling in Europe.

Those cited above were the personnel of the Design Division, when the author arrived in June 1965 as a graduate research assistant working with Roth. The only addition, and the only senior faculty member, was Henry Fuchs who had spent most of his career in industry and was still finding his feet in academia. He joined the group a year after Arnold died. His background was also applied mechanics. At that time Bulkeley was serving as leader of the Division. Within the next four years Keller would be denied tenure. There would be several other departures for the same reason in the ensuing years. Bulkeley would move to an administrative staff position. James Adams, an Arnold Ph.D. who had been working at the Jet Propulsion Laboratory would join the Division. Going forward, Roth, McKim, Fuchs and Adams formed the core faculty group. A little later they were joined by Larry Leifer, who had a master's degree in product design and a doctorate in biomedical engineering from Stanford. Douglas Wilde, who was then a faculty member in Chemical Engineering, would decide that his interest in numerical 
optimization fitted better with the Design Division would transfer into the group. Roth and Leifer continue to be active members of the faculty to this day.

Roth navigated this turbulent environment with apparent ease. His publication record was strong, and he was working with several graduate students, including the author. $\mathrm{He}$ would be promoted and tenured on schedule.

\section{Theoretical Kinematics}

Freudenstein and his students, including Roth, were engaged in translating the classical graphical constructions of Ludwig Burmester for linkage synthesis [1] into algorithms that could be executed on a digital computer. This work went far deeper than a step-by-step translation of the graphical constructions into algebraic equations. Instead the fundamental geometric properties that were the bases of those constructions were expressed algebraically to create algorithms. At the time, digital computers were a very new tool and engineering researchers were still learning how to make use of them. Thus, this work was novel at the time.

Roth's doctoral work was focused on the point path problem and was already moving beyond the classical framework [2]. The geared five-bar mechanism was selected as having the greatest generality from the point of view of single loop linkage synthesis. With appropriate gear ratio selection it becomes a four-bar linkage. This paper also marks the first publication of the "bootstrap method", that will appear several times in this narrative.

The work represents a significant move beyond that of Sandor and Freudenstein in moving beyond the translation of classical, geometrically based linkage theory into 
numerical terms. The difference is that the focus had become the development of solutions that can only be implemented on a computer.

The numerical method Roth and Freudenstein called the bootstrap method has come to be known as homotopy, or continuation [3]. This is a process for numerical solution of systems of nonlinear algebraic equations. In the mechanism context the way it works is to start with a system that has a known solution and is topologically homologous with the system to be solved. The dimensions of the known mechanism are than changed in small steps and the algebraic system is resolved after each step until the mechanism described by the equations becomes identical with the target mechanism.

Another research line that followed directly from Roth's doctoral work was the definitive study of planar cognate linkages and their application in generating multiple solutions to planar linkage synthesis problems [4]. This work is based on the observation that the use of a skew pantograph to generate cognate trajectories need not be restricted to circular and linear paths, as was done, for example, by Roberts [5]. Hence cognates of other types of linkage beside four-bars can be generated. Roth provided examples of six and eight-bar cognate sets. He demonstrated that the path generator for six-bar cognates is a four-bar linkage.

It is difficult to appreciate the importance of some of Roth's early work from the vantage point of today when computational power has increased by many orders of magnitude, and problems that required extremely efficient algorithms to be even solvable are now routinely disposed of by straightforward, brute force methods. That might be said of the next series of papers that extended Burmester's theory into the domain of spatial linkages $[6,7,8]$. 
These three papers are true classics in the literature of linkage synthesis. Taken together they amount to a comprehensive theory of synthesis of spatial linkages to meet finitely separated design position specifications. Professor Roth received the ASME Melville Medal, given for the best paper published in any ASME Transactions journal, for one of these papers. Once again, the bootstrap method was used to solve systems of Figure 1: The fixed and moving congruences of lines distributed in space that correspond to the center point curve and the cubic of stationary curvature of the classical

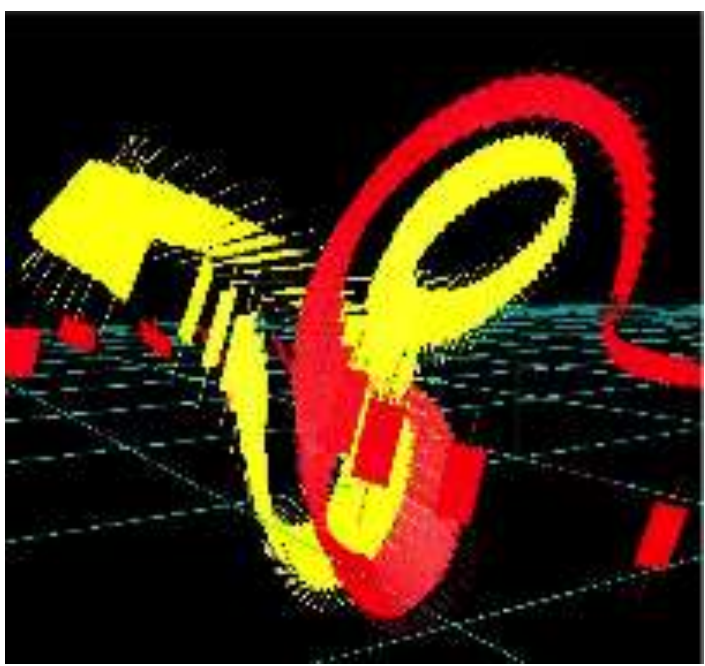
Burmester theory.

nonlinear polynomial equations. Devising methods for solution of such systems of equations marks a continuing theme in Roth's work. The algorithm does, of course, have applications to problems in many areas beyond linkage synthesis and analysis. Not surprisingly, it has been further developed by subsequent workers.

Today we are able to witness the implementation of Roth's spatial synthesis theory via virtual reality. The geometric entities called fixed and moving congruences that play a central role in the theory can be displayed spatially, along with appropriate alphanumeric labels as in Figure 1.

At the same time, Roth and his student Pictiaw Chen were working to unify the theory of synthesis with finitely separated positions with what was known as curvature theory, which could be viewed as collapsing multiple design positions into a single position along with velocity and acceleration specifications in that position $[9,10]$. They extended synthesis with mixed motion specifications into the spatial domain. The theory 
allows the designer to specify positions, velocity screws and accelerations either for planar or spatial motion.

\section{Robotics at Stanford}

Roth, himself, has written [11] that his first introduction to robotics came via a telephone call in 1964. The caller was Fred Terman, the legendary former Dean of

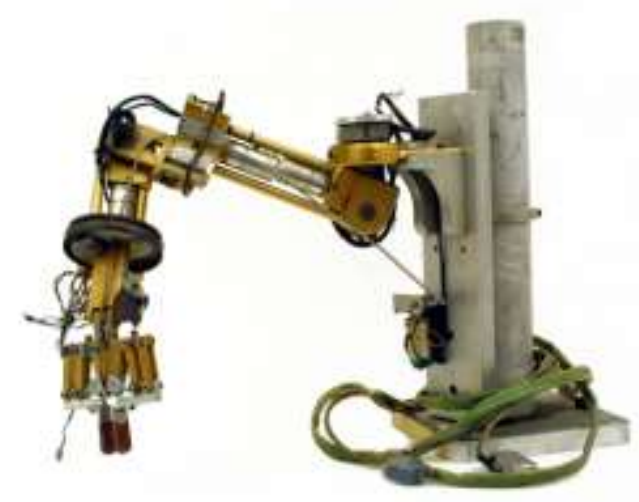

Engineering who was now Provost of Stanford.

Terman informed Roth that Professor John McCarthy in computer science (then a part of the Department of Mathematics) had been Figure 2: Butterfingers: the SAIL Rancho Los Amigos arm. The device was originally designed as an exoskeleton to provide some arm function for a quadriplegic. It was adapted at SAIL to be the laboratory's first computer controlled manipulator.

awarded a large research grant that, in part, involved development of computer controlled manipulators. This grant was, in fact, the foundation of the Stanford Artificial Intelligence Laboratory (SAIL). Someone had suggested that McCarthy should have some contact with mechanical designers. Although Roth had never met Terman, he was the only faculty member whose specialty was mechanism design, so Terman decided to call him.

The collaboration with SAIL resulted in the Hydraulic Arm and, ultimately, the Stanford Arm. In order to get going quickly on computer coordination, the project purchased an orthotic arm from Rancho Los Amigos hospital in Los Angeles. This was, essentially, an exoskeleton intended to provide arm mobility for quadriplegic patients. It was intended that the joint actuators would be controlled in an on-off fashion by means of a bank of switches held in the patient's teeth to be operated by the tongue. The switches 
were replaced by a crude computer interface, and a parallel gripper was mounted outboard of the wrist: Figure 2. The device was programmed to stack blocks. It acquired the name "Butterfingers".

Roth and his students were given the task of designing and building a manipulator specifically for computer control. The thinking in the lab was that computers were fast, so the manipulator needed to be fast to avoid wasting computation time. This led Roth and his students to design the seven degree-of-freedom Hydraulic Arm: Figure 3. The geometry was modeled on the human arm. An innovation was to power the device with rotary hydraulic actuators in order to procure relatively large ranges of motion from the joints. The device was fast. It was also relatively heavy. SAIL was, at the time, housed in a light, wood-framed building, which shook violently every time the arm was operated. There was also a large and noisy hydraulic power supply that sat outside on the veranda. At the time, the computer interface was imperfect, leading to unexpected glitches when the arm would swing wildly with apparent homicidal intent. Eventually a hole was cut in the floor and a large block of concrete was cast as a foundation for the arm. Within the building a booth was constructed, and warning signs were posted, to keep humans out of the robot's working

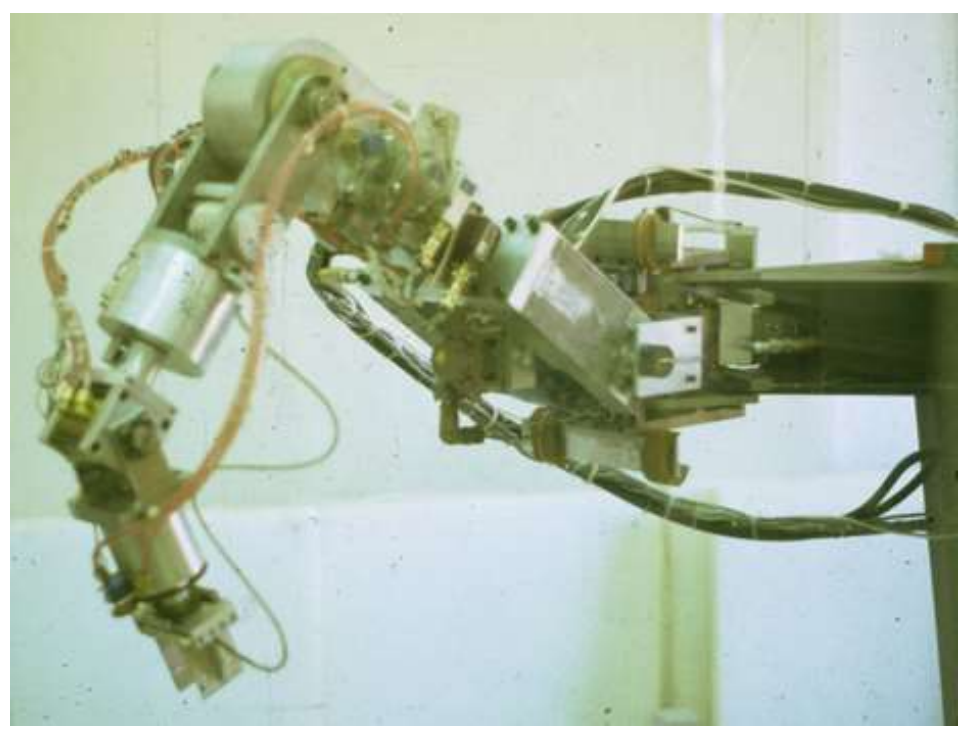

Figure 3: The Stanford Hydraulic Arm. The device was biomimetic, modeled on the degrees of freedom of the human arm. Rotary hydraulic actuators permitted relatively large ranges of joint motion. 
space. The robot also demonstrated that the assumption that it needed to be fast to keep up with the computer controlling it was faulty, by spending much of it's operating time stationary, except for a slight twitch.

This led to the design of the Stanford Arm: Figure 4, which became operational in 1970. In order to overcome deficiencies of the earlier devices it was decided that the ease of controlling electric actuators driving through large ratio speed reducers was more important than the speed of

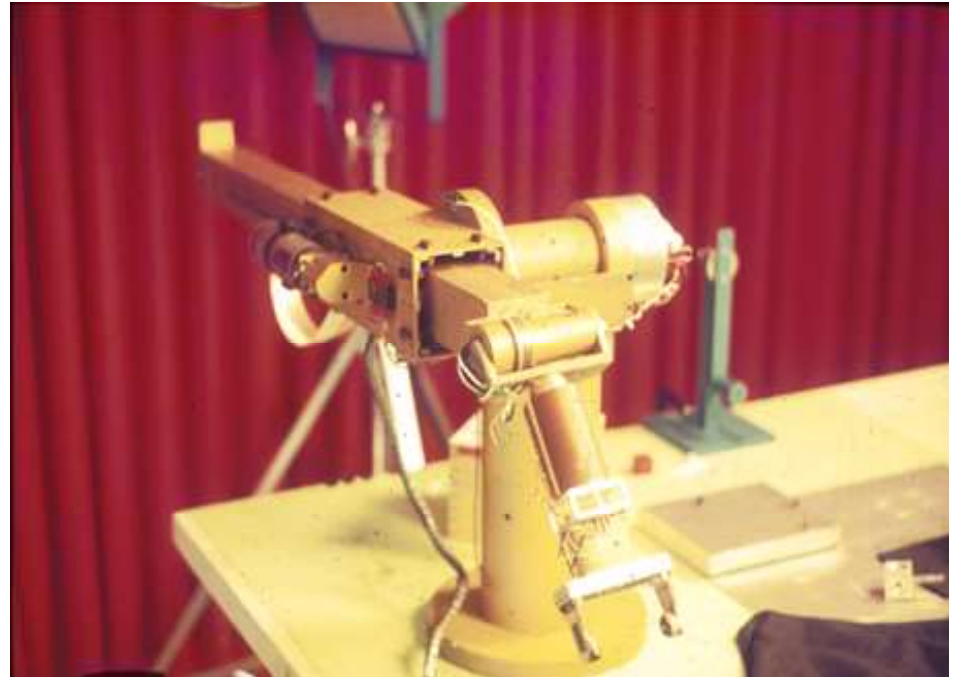

Figure 4: The Stanford Arm. The first computer controlled manipulator successful enough to be produced in multiple copies. Designed by Victor Scheinman under Roth's supervision it entered service in 1970.

hydraulic actuators. In order to permit closed form solution of the coordination mathematics, the rotary elbow was replaced by a prismatic joint providing extension in the radial direction. The shoulder had a vertical axis of rotation followed by an elevation about a horizontal axis, and the wrist had a roll-pitch-roll configuration. In combination with the, relatively slow, speed reduced electric actuators, the lightweight aluminum structure made the device much more compatible with humans working around it than the hydraulic arm. Victor Scheinman, who was Roth's student at the time, executed the design. However, because Roth was on sabbatical leave in the Netherlands in 1969, the author signed Scheinman's engineer's degree thesis. 
The Stanford Arm was not quite the first computer-controlled manipulator, but it was the first successful one. About a dozen copies were made and operated in various laboratories entering the nascent field of digitally controlled robotics. Vic Scheinman, subsequently joined Unimation Inc. He was the primary designer of the Puma series of industrial robots, and of several other commercially successful models. The group of former students, including Vic, Bruce Shimano and Brian Carlisle that was spun off to Unimation eventually became the genesis of Adept Technology.

Roth spent the 1968-69 academic year on sabbatical in the Netherlands with Oene Bottema. Their collaboration resulted in the book: Theoretical Kinematics [12], along with several technical papers.

Before the eighties Roth published very little about his work in robotics, at least in comparison to the volume of his publications in kinematic theory applied to closed-loop mechanisms. Donald Pieper participated in the design of the Hydraulic Arm, and was Roth's co-author in his first paper on robotics: "The Kinematics of Manipulators Under Computer Control" [13] that was presented at the IFToMM World Congress three months after Daniel Whitney's widely recognized paper on the similar subject of resolved motion rate control [14]. That was followed four years later by reference [15] that laid out insights on both hardware and software design.

In reference [14], and in Pieper's doctoral dissertation, a method for interpolating a path of desired geometry between programmed end-effector positions is presented. This work is fundamental to the coordination software of most industrial robots. 


\section{The Orm}

Reference [15] contains several seminal ideas. The orm was one of the first concepts of a continuous curvature robot analogous to an elephant's trunk. This prototype was conceived as having a binary actuation system. It had a spine of circular plates articulated with universal joints, and eight pneumatic balloon actuators symmetrically arranged between each pair of spine plates. Each actuator operated in an on-off mode. The paper also contained early work on the general, six degree of freedom inverse position problem. All of these are concepts that have since generated voluminous research literatures.

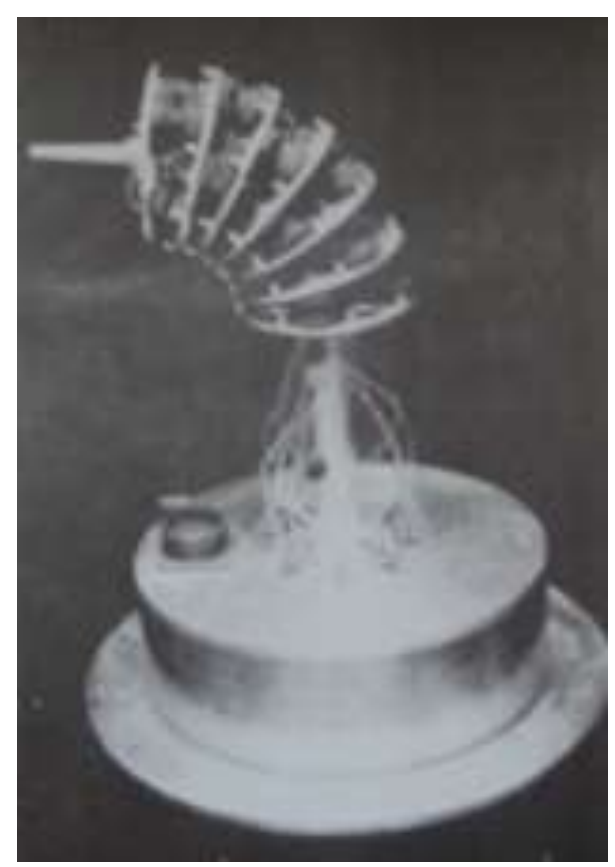

Figure 5: The Orm. This was an approximation to a continuously curved manipulator structure. Each pair of segment plates were separated by eight symmetrically placed pneumatic balloon actuators

\section{Hands}

Working with Roth, J. Kenneth Salisbury developed several devices. Most notable among them was the Stanford/JPL hand. This was an agile three-fingered gripper actuated by a sophisticated tendon system. The fingers were opposable permitting a variety of finger manipulation strategies.

This work, described in reference [18], was also an early contribution to the fundamental kinematics of parallel mechanisms. It included a number of concepts that are now regarded as being fundamental. In particular, the work includes the original definition of the grip matrix. 
As in much of Roth's work, the theory developed both guided the design of hardware experiments, and was validated by those experiments. In this case the hardware developed became the Stanford/JPL Hand.

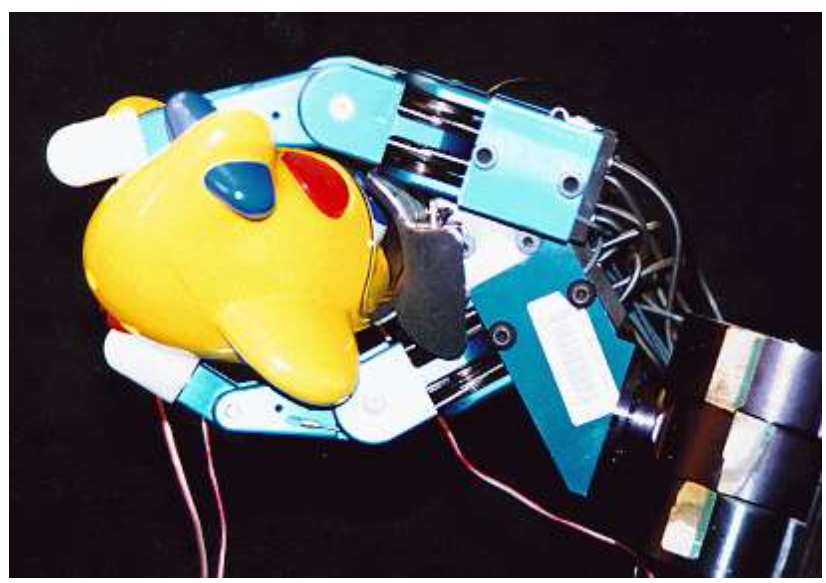

\section{Theoretical Kinematics Again}

\section{Reference [19] extended the}

Figure 6: The Stanford/JPL hand. The three-fingered gripper was actuated by means of a sophisticated tendon system. The device was designed by J. Kenneth Salisbury under Roth's supervision.

mathematics used for coordination of

robotics to more general structures that include both serial and parallel mechanism components. The driving idea was that serial chains allow access to large working volumes, but precise movements are better achieved by parallel manipulator structures.

Reference [20] brings together several threads found throughout Roth's work. The paper describes a very sophisticated use of dialytic elimination methods to solve one of the great challenges of spatial kinematics: the inverse position kinematics of the general $6 \mathrm{R}$ serial chain, and its equivalent, the general $7 \mathrm{R}$ loop. It's central contribution is the use of trigonometric structure to "manufacture" additional equations with the same power products.

\section{Human Development}

No review of Bernard Roth's career would be complete without reference to his lifelong interest in the development of human capabilities. Formally, he has taught the course ME 315: The Designer in Society for many years. He also co-organized and 
taught a series of Summer Workshops on human creativity with colleagues Rolf Faste and Douglas Wilde from 1989 to 2003 [21]. He was invited to teach similar workshops on creativity in India, Taiwan, Singapore, Japan, Sweden and other countries. In 2015 he published the book: The Achievement Habit [22] that presents the central ideas from these workshops.

Professor Roth has always had a continuing interest and interaction with current and former students, and with others in the professional community.

In 2004 Roth joined with David Kelley and several other colleagues to found the Hasso Plattner Institute of Design at Stanford, locally known as the d.School. This has been a major focus of his activities in recent years. He currently holds the title of Academic Director of the Institute. The credo of the d.School is:

"We believe everyone has the capacity to be creative. The Stanford d.school is a place where people use design to develop their own creative potential."

The d.School offers a portfolio of courses designed to boost the creativity of the students taking them, typically at masters degree level. The Institute also offers many workshops to external participants under the general heading of design thinking.

\section{Leadership in the Professional Community}

In a formal capacity, Roth filled a substantial number of leadership positions in the professional community. Most of these activities occurred so long ago that people active in the field no longer remember them. Notable contributions included Chairmanship of the ASME Design Engineering Division in 1981 and '82. Some will remember his

luncheon speech at the ASME Design Engineering Technical Conference in 1990. He 
was President of IFToMM (1980-83), and a member of the Executive Council (1976-83).

$\mathrm{He}$ is, or was, a member of the boards of directors of eight companies and non-profit organizations.

Roth has always been willing to make his views known, even when those views were not those of the majority in the community. The publications cited here $[23,24]$ express his feelings about engineering research sponsorship by military agencies. He has never accepted such sponsorship of his own research.

\section{Summary}

In this review paper we have endeavored to cover Roth's most important contributions to technical research, to the academic department in which he has spent his entire career, to the professional community, and to society in general. That is a tall order in a brief paper format, but these threads may be further explored through the publications cited. 


\section{References}

[1] Burmester, Ludwig, Lehrbuch der Kinematik, Verlag von Arthur Felix, Leipzig, 1888.

[2] Roth, B., Freudenstein, F., "Synthesis of Path-Generating Mechanisms by Numerical Methods," J. Eng. for Industry, Vol. 85, No. 3, 1963, pp. 298-307.

[3] Roth, B., Freudenstein, F., "Numerical Solution of Systems of Nonlinear Equations," J. of the Association for Computing Machinery, Vol. 10, No. 4, 1963, pp. 550-556.

[4] Roth, B. "On the Multiple Generation of Coupler Curves," J. of Eng. for Industry, Vol. 87, No. 2, 1965, pp. 177-183.

[5] Roberts, S. "On Three-bar Motion in Plane Space," Proc. London Mathematical Society, v. 7, 1875, pp. 14-23.

[6] Roth, B. "Finite Position Theory Applied to Mechanism Synthesis," J. of Applied Mechanics, v. 34, no. 3, 1967, pp. 599-605.

[7] Roth, B. "On the Screw Axes and Other Special Lines Associated with Spatial Displacements of a Rigid Body,” J. of Eng. for Ind., v. 89, no. 1, 1967, pp. 102110.

[8] Roth, B. "The Design of Binary Cranks with Revolute, Cylindric, and Prismatic Joints," J. of Mechanisms, v. 3, no. 2, 1968, pp. 61-72.

[9] P. Chen and B. Roth, "A Unified Theory for the Finitely and Infinitesimally Separated Position Problems of Kinematic Synthesis," J. Eng. for Industry, Feb. 1969, Vol.91, pp. 203-208. 
[10] P. Chen and B. Roth, "Design Equations for the Finitely and Infinitesimally Separated Position Synthesis of Binary Links and Combined Link Chains, J. Engineering for Industry, Feb. 1969, Vol.91, pp. 209-219.

[11] Roth, B., "Foreword," in Springer Handbook of Robotics eds. Siciliano, B., Khatib, O. $2^{\text {nd }}$ Edition 2016, pp. v-ix.

[12] Bottema, O., Roth B., Theoretical Kinematics, North Holland Publishing Company, 1979.

[13] Pieper, D.L., Roth, B., "The Kinematics of Manipulators Under Computer Control," Proc. Second International Congress on the Theory of Machines and Mechanisms, Zakopane, Poland, v. 2, September, 1969, pp. 159-169.

[14] Whitney, D.E., "Resolved Motion Rate Control of Manipulators and Human Prostheses," IEEE Trans. Man, Machine \& Cybernetics, Vol. 10, No. 2, June 1969, pp. 47-53.

[15] Roth, B., Rastegar, J., Scheinman, V., "On the Design of Computer Controlled Manipulators," Proc. First CISM-IFToMM Symposium on Theory and Practice of Robots and Manipulators, Udine, Italy, 1973, pp. 93-113.

[16] Roth, B., "Performance Evaluation of Manipulators from a Kinematic Viewpoint, Performance Evaluation of Programmable Robots and Manipulators, National Bureau of Standards, NBS SP-459, 1976, pp. 39-61; also published in: Cours de Robotique, v. 1, pp. 235-263, Toulouse, France, September 1976.

[17] Shimano, B., Roth, B. "On Force Sensing Information and Its Use in Controlling Manipulators," IFAC Proceedings, Vol. 10, No. 11, 1977, pp. 119-126. 
[18] J.K. Salisbury and B. Roth, "Kinematic and Force Analysis of Articulated Mechanical Hands," J. Mechanisms, Transmissions, and Automation in Design, Vol. 105, 1983, pp. 35-41.

[19] K. J. Waldron, M. Raghavan and B. Roth, "Kinematics of a Hybrid Series-Parallel Manipulation System," Trans. ASME J. Dynamic Systems, Measurements and Controls, Vol. 111, No. 2, June 1989, pp. 211-221.

[20] M. Raghavan and B. Roth, "Inverse Kinematics of the General 6R Manipulator and Related Linkages," J. Mechanical Design, Vol. 115, 1993, pp. 502-508.

[21] B. Roth, R.A. Faste and D.J. Wilde, "Integrating Creativity into the Mechanical Engineering Curriculum," Innovations in Engineering Design Education, ASME, 1993, pp. 93-98.

[22] Roth, B., The Achievement Habit, Harper Collins, 2015.

[23] B. Roth, "The Moral Arguments Against Military Research," Ethical Issues Associated with Scientific and Technological Research for the Military, ed. C. Mitcham and P. Siekevitz, Ann. N.Y. Academy of Sciences, Vol. 577, 1990, pp. $21-33$

[24] B. Roth, "Robots and the Military: Do They Really Need Each Other?" CPSR Newsletter, Vol. 5, No. 3, 1987, pp. 1-8 